Société d'histoire de la révolution de 1848 et des

révolutions du XIXe siècle

43 | 2011

L'ordre électoral : savoirs et pratiques

\title{
Corinne LEGOY, L'enthousiasme désenchanté. Éloge du pouvoir sous la Restauration, Paris, Société des études robespierristes, 2010, 252 p. ISBN :
} 978-2-908327-70-0. 25 euros.

Hélène Becquet

\section{OpenEdition}

Édition électronique

URL : http://journals.openedition.org/rh19/4179

DOI : $10.4000 /$ rh 19.4179

ISSN : $1777-5329$

Éditeur

La Société de 1848

\section{Édition imprimée}

Date de publication : 13 novembre 2011

Pagination : 161-164

ISSN : 1265-1354

\section{Référence électronique}

Hélène Becquet, « Corinne LEGOY, L'enthousiasme désenchanté. Éloge du pouvoir sous la Restauration, Paris, Société des études robespierristes, 2010, 252 p. ISBN : 978-2-908327-70-0. 25 euros. », Revue d'histoire du XIXe siècle [En ligne], 43 | 2011, mis en ligne le 13 juillet 2012, consulté le 21 septembre 2020. URL : http://journals.openedition.org/rh19/4179; DOI : https://doi.org/10.4000/rh19.4179

Ce document a été généré automatiquement le 21 septembre 2020

Tous droits réservés 


\title{
Corinne LEGOY, L'enthousiasme
} désenchanté. Éloge du pouvoir sous la Restauration, Paris, Société des études robespierristes, 2010, $252 \mathrm{p}$. ISBN : 978-2-908327-70-0. 25 euros.

\author{
Hélène Becquet
}

1 L'ouvrage de Corinne Legoy s'inscrit dans le renouvellement de l'historiographie des monarchies censitaires, à l'instar d'autres livres récents ${ }^{1}$. L'auteur nous invite à la découverte de tout un univers littéraire oublié, celui de la littérature d'éloge. Comme le rappelle Alain Corbin dans sa préface, les thuriféraires ont globalement mauvaise presse dans l'historiographie moderne et contemporaine. On ne voit très souvent dans leurs écrits que médiocrité et servilité. À l'opposé de ces clichés, Corinne Legoy réintègre cette littérature dans son contexte politique et social, lui redonne sens et profondeur et restitue l'émotion dont elle était porteuse. Elle ouvre ainsi une porte nouvelle sur les sensibilités politiques du premier XIX ${ }^{\mathrm{e}}$ siècle.

Dans sa première partie, "Le ministère de la gloire ", l'auteur nous présente ces thuriféraires si souvent méprisés. Elle dépeint un groupe essentiellement masculin, majoritairement provincial d'origine, dans lequel la noblesse est surreprésentée (avec quelques noms prestigieux : Ségur, La Rochefoucault-Liancourt), plus très jeune, puisque les deux tiers d'entre eux ont connu la Révolution. Ces panégyristes n'ont bien souvent pas fait d'études supérieures et se sont lancés, pour un quart d'entre eux, dans des carrières, généralement peu rémunératrices, de journalistes ou de polygraphes, parfois à la suite d'accidents de parcours. Au total, le monde des thuriféraires apparaît non seulement morcelé mais clivé. À côté d'une bohême littéraire parfois franchement miséreuse, se dressent d'honorables membres des sociétés savantes et académies de province et un Lamartine ou un Hugo. Après cette description minutieuse du milieu socio-culturel des panégyristes, l'auteur nous montre des écrivains libres - l'impulsion 
directe de l'État étant relativement faible - et le plus souvent sincères, la plupart d'entre eux n'ayant écrit que pour les Bourbons. Les thuriféraires, comme nombre d'écrivains de la période, revendiquent une forme de magistère et sont persuadés de l'efficacité de leur parole. Celle-ci nait de l'émotion qui justifie l'écriture de l'éloge et apparaît comme la mesure de l'engagement de l'écrivain en faveur de la cause monarchique.

Dans sa deuxième partie, Corinne Legoy s'attache à l'écriture même de l'éloge, en trois temps. Elle souligne d'abord la temporalité paradoxale de cette parole de gloire. Destinée, en théorie, à perdurer et donc à s'inscrire en dehors de toute temporalité, elle est générée par des événements et un contexte précis dont elle apparaît malgré tout indissociable. L'écriture des thuriféraires reconstruit donc l'histoire selon une temporalité qu'elle invente. Le temps est parfois comme suspendu, d'autre fois contracté, souvent cyclique. Deuxième caractéristique, l'écriture thuriféraire repose sur l'émotion, celle qu'elle décrit et celle qu'elle provoque. La parole de gloire multiplie ainsi les mises en scènes sentimentales et les exempla qui doivent, d'un même mouvement, toucher, instruire et unir. Enfin, tout le discours des panégyristes a pour but de refonder l'ordre social. Cela signifie d'abord glorifier la figure royale, réinventée à partir des topoi de la tradition monarchique et du repoussoir absolu que représente Napoléon. Cela veut dire aussi vanter les vertus d'une société bien ordonnée, hiérarchisée, religieuse, selon le modèle contre-révolutionnaire, avec cependant des nuances selon les écrivains.

Dans sa troisième partie, «l'apogée crépusculaire d'une pratique ", l'auteur cherche à cerner la réception de ces œuvres et, pour ce faire, s'intéresse au contexte de production des éloges. Elle commence par rappeler la pratique courante de la versification au début du XIX ${ }^{\mathrm{e}}$ siècle. L'écriture poétique est relativement banale et son succès se perçoit dans l'engouement que suscitent recueils et pièces de poésie, largement diffusés dans la presse. D'une certaine façon, l'éloge n'est qu'une souscatégorie d'un genre très répandu. Il est, par ailleurs, souvent destiné à des manifestations bien précises au cours desquelles sa diffusion est assurée auprès d'un public plus ou moins large : cérémonies ordonnées par le pouvoir, festivités organisées par les cercles royalistes, ou encore concours des sociétés savantes. La pratique de l'éloge s'avère donc fort vivace. Pourtant, elle jette ses derniers feux sous la Restauration. L'écriture thuriféraire est attaquée sur tous les fronts : alors que les normes stylistiques se modifient, les critiques pleuvent sur ce qu'on dénonce souvent comme de mauvais vers; alors que l'expression politique se démocratise, le genre devient suranné, vaguement élitiste; alors que l'écrivain doit être indépendant pour exercer son magistère, le panégyriste est soupçonné ou de servilité ou de versatilité. Finalement, la parole de gloire et ses porteurs sont condamnés au nom d'une modernité politique et littéraire à laquelle ils ont pourtant contribué à certains égards.

5 L'enquête de Corinne Legoy rénove ainsi l'histoire des pratiques politiques et culturelles du premier XIX ${ }^{\mathrm{e}}$ siècle. Les rares regrets que l'on peut formuler concernent l'organisation du propos à certains endroits. Certaines idées auraient sans doute gagné en force à être davantage hiérarchisées (dans la première partie, sur le portrait de groupe des auteurs); il y a parfois des redites ou des dissociations qui peuvent quelque peu dérouter le lecteur (le chapitre 3 de la troisième partie, qui concerne le mécénat, semblerait mieux s'articuler avec la première partie, où la question est déjà abordée). Cela n'atténue cependant en rien l'intérêt de l'ouvrage qui découvre un pan largement 
sous-exploité de la littérature politique. Si les grandes qualités internes de ce livre sont insuffisamment mises en valeur par sa présentation matérielle, il faut souligner la présence bienvenue d'un CD-ROM d'accompagnement.

\section{NOTES}

1. . Par exemple Emmanuel Fureix, La France des larmes : deuils politiques à l'âge romantique (1814-1840), Seyssel, Champ Vallon, 2009; ou Gilles Malandain, L'introuvable complot : attentat, enquête et rumeur dans la France de la Restauration, Paris, Éditions de l'EHESS, 2011. 